\title{
Resenha do livro Cartografias criativas: da razão cartográfica às mídias móveis, de Juliana Franco
}

Clayton Policarpo'

Embora hoje pareça-nos impossível assentir com os cenários apocalípticos dos primórdios da internet, que apontavam para um futuro com relações desprovidas de materialidade e uma inevitável dicotomia entre virtual e real, a facilidade de acesso a serviços remotos via aplicativos e mídias móveis, como temos vivenciado nos últimos anos, é uma conquista muito recente. No Brasil, é a partir do ano de 2010 que se torna possível identificar uma popularização dos dispositivos sem fio - com a consolidação do sucesso do iPhone e a chegada do iPad da Apple, o que também assegurou um crescimento da oferta de smartphones a preços módicos - que se soma à redução dos custos de pacotes de internet para celular, em função da implementação do Plano Nacional de Banda Larga (PNBL), proposto pelo governo federal no mesmo ano.

Com as mídias móveis se inicia uma importante mudança de perspectiva: passamos da condição de estarmos conectados para sermos conectados. Não por acaso, o salto tecnológico e cognitivo observado na última década, propiciado pela recente evolução das tecnologias em rede, é sem precedente na história da humanidade e ainda carece de investigações sistemáticas. Neste sentido, o livro de Juliana Rocha Franco busca suprir uma lacuna na produção acadêmica brasileira ao direcionar o foco de sua abordagem para um panorama da criação em tecnologias georreferenciadas, ao tempo que oferece uma ampla base conceitual e metodológica, imprescindível para os interessados em aprofundar o conhecimento no tema.

Editado pela Appris Editora e com lançamento previsto ainda em 20I9, Cartografias criativas: da razão cartográfica às mídias móveis conta com prefácio de Lucia Santaella, pesquisadora de renome internacional por sua produção nas áreas de semiótica, tecnologia e cibercultura, além de uma das pioneiras no estudo de mídias locativas no Brasil. A publicação é fruto da pesquisa de doutorado de Franco, desenvolvida na PUC-SP com período de estágio na University of Maryland (EUA). Estruturado em cinco

I Doutorando em Tecnologias da Inteligência e Design Digital pela PUC-SP.

TLattes: lattes.cnpq.br/880I492560768204. E-mail: clayton.policarpo@gmail.com. 
capítulos, além das seções de apresentação e considerações finais, o livro propõe alçar compreensão a respeito da produção em tecnologias móveis, em especial os seus entrecruzamentos com o campo da arte. A resenha aqui disposta se propõe a um diálogo com algumas das principais problemáticas levantadas por Juliana Rocha Franco, a partir de apontamentos realizados acerca dos respectivos capítulos que compõem o livro.

O surgimento do termo "mídias locativas" se dá em 2003, "em um contexto de workshops, festivais de Media Art e uma efervescência de listas de discussão online" (Franco, 20I9, p. 20). A princípio pensado como uma categoria para diferenciar entre as abordagens artísticas e usos comerciais das plataformas que oferecem "serviços baseados em localização" (ibid.), o termo hoje tende a englobar uma profusão de aplicações e processos que se utilizam de tecnologias móveis de comunicação: de criações no campo da arte a campanhas publicitárias, passando por ativismos políticos, games, mapeamento, vigilância, realidade aumentada etc. André Lemos, um dos responsáveis pela difusão de pesquisa sobre o tema no Brasil, estipula algumas categorias para classificação das mídias locativas a partir de suas aplicações e tecnologias que as integram (LEMos, 2008). Contudo, entre os pesquisadores da área, não há um consenso quanto as suas definições e limites. Talvez, a dificuldade em cercear o uso do próprio termo "mídias locativas", e mesmo em postular fronteiras para suas aplicações, seja um sintoma da destituição de um binarismo na cultura que preza por classificações opositivas e excludentes.

No primeiro capítulo, intitulado "Notas sobre o espaço e uma proposta alternativa ao pensamento binário”, a autora propõe uma investigação em relação ao modelo dualista que dita a tônica do pensamento ocidental, desde, pelo menos, a chamada Modernidade. Tal dicotomia, que se mostra insuficiente diante do advento das mídias locativas, é confrontada com uma série de autores e metodologias que desenvolvem uma base de pensamento antidualista, dos quais destacam-se a semiótica de Charles Sanders Peirce (I839-I9I4) e a Teoria Ator-Rede de Bruno Latour (I947-) como caminhos possíveis para estruturar um raciocínio que escapa ao molde cartesiano.

Uma virada espacial marca a consolidação da ideia de que "relações espaciais devem ser compreendidas não apenas como um pano de fundo ou cenário para eventos, um recipiente vazio a ser preenchido com ações ou movimentos, ou algo para ser tratado como a priori ou fixo" (p. 40). A concepção de espaço como um continuum corrobora no entendimento da hibridização entre físico e virtual, que já não podem mais ser enca- 
rados como modalidades que se anulam ou meros receptáculos para as relações que acontecem no tempo.

Segundo Franco, “o ato de mapear, representar e comunicar conhecimento espacial é uma atividade presente de alguma maneira em quase todas as sociedades humanas" (p. 6I). No capítulo dois, "Mapas e a razão cartográfica”, a autora resgata registros cartográficos produzido ao longo da história da humanidade, desde as primeiras civilizações até iniciativas contemporâneas, que se fazem valer de aparatos digitais. Já no capítulo três, "Da visão panóptica a partilha do sensível”, é evocado o potencial de vigilância e controle dos mapeamentos e mídias locativas, que num certo ponto remete à sociedade panóptica mencionada por Michel Foucault, ao permitir uma observação distanciada das zonas de convívio. Aqui também são resgatados alguns conceitos de um outro pensador francês, Jacques Rancière. Em sua partilha do sensível, Rancière aborda temas como arte, política e resistência. Embora tais fenômenos se apresentem como contraditórios, na leitura do autor são interdependentes e contribuem para a organização do sensível de uma sociedade e no entendimento do papel das relações e dissensos que daí emergem. A metáfora de Eros e Thanatos, proposta por Lucia Santaella (20I0), também é citada por Franco para elucidar as contradições e ambiguidades inerentes às tecnologias locativas.

$\mathrm{Na}$ década de I990, com o aparecimento de espaços virtuais de interação, desencadearam-se uma série de prognósticos acerca da morte das cidades, tema abordado no capítulo quatro: “Do fim das geografias às interfaces urbanas". Nos dias atuais, diante das imbricações entre tecnologias móveis e meio, fica evidente o equívoco promulgado por alguns pesquisadores que postularam o fim da experiência urbana em prol de uma digitalização da vida. O trabalho Can You See Me Now (200I) desenvolvido pelo coletivo britânico Blast Theory em parceria com o Mixed Reality Lab é uma experiência emblemática neste sentido. Em uma espécie de "performance jogo", CYSMN se configura como evento de perseguição que acontece no cruzamento de ambientes online e físico. Em uma região pré-mapeada da cidade, os participantes são divididos em dois grupos e atuam em ambas dimensões do espaço. Ao incorporar a cidade como um elemento da narrativa, o trabalho reforça uma possível justaposição de diferentes camadas que coexistem de maneira simultânea nas cidades contemporâneas.

Ainda no quarto capítulo, a autora traz outros trabalhos desenvolvidos no início dos anos 2000 que corroboram na reflexão acerca da cons- 
trução de espacialidades híbridas, bem como o caráter social que lhes é característico. A exemplo as propostas Urban Tapestries (2002-2004), desenvolvida pelo grupo Proboscis (p. I43) e Amsterdam Realtime (2000) (p. I44-I48), de Esther Polak, Jeroen Kee e Waag Society.

No intuito de assimilar conhecimento acerca da apropriação das mídias locativas por artistas, o capítulo cinco "A cartografia expandida das mídias locativas" realiza um levantamento do uso de mapas na produção estética ao longo do século XX, e as mudanças no entendimento da arte e na percepção do espaço, promovidas no período. O mapa passa a ser incorporado como elemento na produção estética nos movimentos Dadá e Surrealista (p. I59 apud Wood, 20I0) e, desde então, se faz presente nas mais diversas manifestações artísticas. Dentre algumas experiências citadas, que possibilitaram as práticas locativas contemporâneas, estão: as proposições Situacionistas da década de ı960, equiparadas, por vezes, de maneira leviana, a um experimento precursor das mídias locativas; as investigações cartográficas de Marcel Duchamp; o uso do grid na pintura moderna, em especial na obra de Piet Mondrian; a desmaterialização da arte nas experiências do minimalismo e da land art que, gradativamente, deslocam a produção estética do objeto artístico para o campo processual.

A contextualização das diversas esferas que integram as mídias locativas, desde o espaço da cidade, tanto do ponto de vista estrutural como social, e as suas representações cartográficas possíveis; a evolução das tecnologias em rede, bem como as ambivalências que lhes são intrínsecas; e um levantamento minucioso das manifestações estéticas predecessoras das atuais obras locativas, evidenciam o cuidado da autora em integrar à pesquisa as múltiplas abordagens que perpassam as práticas em mídias móveis. As Cartografias Criativas são colocadas como interferências ou fissuras, que mais do que buscar uma cisão com o meio que ocupam ou mesmo estratégias para invalidar a cartografia tradicional, atuam de maneira pontual e provisória, em modelos hierarquicamente pré-estabelecidos. Tais interferências "promovem alterações em nossas percepções e visões de mundo" (Franco, 20I9, p. 204). Como colocado pela autora "trata-se de compreender a Cartografia não somente, mas, sobretudo, como fato e fenômeno de linguagem no qual o espaço se configura como tecido vivo das relações sociais e campo de investimentos simbólicos" (ibid.). 


\section{Referências}

FRANCO, Juliana Rocha. Cartografias criativas: da razão cartográfica às mídias móveis. Curitiba: Appris, 20I9.

Lemos, Andre. Mídia locativa e territórios informacionais. In:

Santaella, Lucia; Arantes, Priscila (org.). Estéticas tecnológicas: novos modos de sentir. São Paulo: EDUC, 2008. p. 207-230.

Santaella, Lucia. Mobile and locative media: in between Thanatos and Eros. In: Firmino, R. J.; DuARTE, F. et al. (orgs.). ICTs for mobile and ubiquitous urban infrastructures: surveillance, locative media, and global networks. Hersey: Information Science Reference, 20IO. p. 294- 3II. 